\title{
Aplicação pré-colheita de reguladores vegetais visando retardar a maturação de ameixas 'Laetitia'
}

\author{
Preharvest spraying with plant regulators aiming fruit maturity delay of 'Laetitia' plums
}

\author{
Cristiano André Steffens ${ }^{\mathrm{I} *}$ Cassandro Vidal Talamini do Amarante ${ }^{\mathrm{I}}$ Ricardo Chechi $^{\mathrm{I}}$ \\ João Paulo Generoso Silveira' Auri Brackmann ${ }^{\text {II }}$
}

RESUMO

O objetivo deste trabalho foi avaliar os efeitos de reguladores vegetais e da data de colheita sobre a maturação de ameixas 'Laetitia'. Os tratamentos avaliados foram: controle, aminoetoxivinilglicina (AVG; 125 $\mathrm{mg} \mathrm{L}^{-1}$ ), 1-metilciclopropeno (1-MCP; $\left.70 \mu \mathrm{g} \mathrm{L}^{-1}\right)$ e ácido giberélico $\left(G A_{3} ; 100 \mathrm{mg}^{-1} \mathrm{~L}^{-1}\right)$ em combinação com duas datas de colheita (11/01/2007 e 25/01/ 2007). $\mathrm{O} \mathrm{GA}_{3}$ foi aplicado 14 dias antes da primeira colheita, enquanto AVG e 1-MCP foram aplicados sete dias antes da primeira colheita. $O$ experimento seguiu o delineamento em blocos ao acaso com quatro repetições. Os reguladores de crescimento, em geral, retardaram as alterações da cor da epiderme e mantiveram a textura dos frutos, com os maiores valores de resistências à compressão e à penetração de polpa. A força necessária para a ruptura da epiderme foi maior no tratamento com 1-MCP. O tratamento controle apresentou os maiores teores de sólidos solúveis (SS). O atraso na colheita reduziu a textura dos frutos, a acidez titulável e o teor de SS, mas proporcionou frutos mais vermelhos. No entanto, nos frutos tratados com os reguladores, a evolução da maturação foi retardada.

Palavras-chave: 1-metilciclopropeno, ácido giberélico, aminoetoxivinilglicina, etileno, data de colheita.

\section{ABSTRACT}

The objective this research was to evaluate the effects of preharvest spraying with plant regulators and harvest date on the fruit maturity of 'Laetitia' plums. The treatments evaluated were: control (untreated), aminoethoxyvinylglycine [AVG; at $125 \mathrm{mg}$ (a.i.) $\mathrm{L}^{-1}$ ], giberellic acid [GA; at 100mg (a.i.)

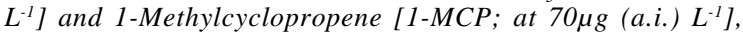
combined with two harvest dates (01/11/2007 and 01/25/2007). The $G_{3}$ was sprayed 14 days before the first harvest, while AVG and 1-MCP were sprayed 7 days before the first harvest. The experiment followed the randomized block design with four replications. In general, the plant regulators delayed changes in skin color and preserved fruit texture, providing the highest resistances values for flesh compression and fresh penetration. The force for skin rupture was highest in treatment with 1-MCP. The control treatment showed the highest levels of soluble solids content (SSC). The treatments had no affect on red color of the fruit. Delays in harvest reduced fruit texture, titratable acidity and SSC, and increased fruit red color, however, treatment with plant regulators delayed changes in fruit maturity.

Key words: 1-methylcyclopropene, gibberellic acid, aminoethoxyvinylglycine, ethylene, harvest date.

\section{INTRODUÇÃO}

O período de colheita de ameixas 'Laetitia', devido a sua rápida maturação, é de cerca de duas semanas. Esse curto período não permite que toda a produção seja colhida no ponto ideal de maturação, o que pode reduzir a vida pós-colheita dos frutos e aumentar as perdas durante o armazenamento e a comercialização. A utilização de reguladores vegetais pode atrasar a maturação e a colheita de frutos, possibilitando racionalizar o uso de mão-de-obra na colheita e reduzir as perdas durante $\mathrm{o}$ armazenamento.

Em maçãs, a aplicação pré-colheita de aminoetoxivinilglicina (AVG) atrasa a maturação dos frutos (AMARANTE et al., 2002; STEFFENS et al., 2005a e 2006) e melhora a manutenção da qualidade dos frutos durante o armazenamento (STEFFENS et

IDepartamento de Agronomia, Universidade do Estado de Santa Catarina (UDESC), Lages. Av. Luis de Camões, 2090, Bairro Conta Dinheiro, 88520-000, Lages, SC, Brasil. E-mail: steffens@cav.udesc.br. *Autor para correspondência.

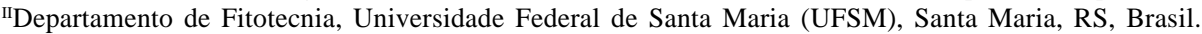


al., 2005b). Esse regulador inibe a síntese do etileno, retardando assim todos os eventos fisiológicos estimulados por esse fitormônio. Na maçã, o AVG reduz a queda pré-colheita de frutos e pode atrasar a colheita em até 15 dias (AMARANTE et al., 2002; STEFFENS et al., 2005a), dependendo da época e dose de aplicação, pois retarda o amarelecimento dos frutos, a perda de firmeza e a degradação de ácidos e de amido (STEFFENS et al., 2006). A aplicação pré-colheita de AVG proporciona maçãs mais verdes, com maior firmeza de polpa, acidez titulável (AT) e sólidos solúveis (SS), além de menor incidência de podridões e de distúrbios fisiológicos durante o armazenamento (STEFFENS et al., 2005b). Em ameixas, o AVG pode retardar a maturação, porém seu efeito é dependente da cultivar (PETRI et al., 2005).

A aplicação pré-colheita de ácido giberélico $\left(\mathrm{GA}_{3}\right)$ retarda a maturação de caqui, reduzindo o amarelecimento dos frutos e proporcionando maior firmeza de polpa, AT e peso de frutos e menor ocorrência de podridões após o armazenamento (FERRI et al., 2002 e 2004). Em pêssegos, tanto o AVG, quanto o GA, aplicados em pré-colheita, apresentaram efeito positivo no controle da maturação dos frutos (AMARANTE et al., 2005).

O 1-metilciclopropeno (1-MCP) é um poderoso antagonista do etileno por se ligar ao receptor desse fitormônio (DAL CIN et al., 2006). DAL CIN et al., (2006) consideram que o primeiro passo da rota de transdução de sinal, isto é, a ligação do etileno ao receptor, é um ponto de regulação altamente efetivo no processo de amadurecimento induzido pelo etileno. A aplicação pós-colheita desse composto tem apresentado forte efeito no controle do amadurecimento de frutos, como, por exemplo, em maçã 'Gala' (BRACKMANN et al., 2004) e em ameixa 'Laetitia' (ARGENTA et al., 2003). No entanto, considerando o mecanismo de ação do 1-MCP, é possível que este também apresente efeito no retardo da maturação quando aplicado na pré-colheita. Em citros, a aplicação a campo de uma solução aquosa de 1-MCP reduziu a abscisão foliar induzida pelo ethephon e aumentou a força necessária para destacar o fruto da planta (POZO et al., 2004).

O objetivo deste trabalho foi avaliar os efeitos da aplicação pré-colheita de AVG, GA 3 e 1-MCP e da data de colheita sobre a maturação e qualidade de ameixas ‘Laetitia'.

\section{MATERIAL E MÉTODOS}

O experimento foi conduzido no ano agrícola de 2006/2007 com ameixeiras da cultivar 'Laetitia’, em um pomar comercial de plantio adensado, apresentando um espaçamento de dois metros, entre plantas, e de quatro metros entre fileiras (1250 plantas ha-1), localizado no Município de Lages, Santa Catarina (SC). Os tratamentos consistiram na combinação de pulverização pré-colheita das plantas com AVG (ReTain $^{\circledR} ; 15 \%$ de ingrediante ativo - i.a.), GA 3 (ProGibb $^{\circledR} ; 10 \%$ de i.a.) e 1-MCP (AgroFresh ${ }^{\circledR} ; 0,43 \%$ de i.a.), com duas datas de colheita (11/01/2007 e 25/01/ 2007). Foi utilizado pulverizador pressurizado, adicionando-se à calda o espalhante adesivo Silwet ${ }^{\circledR}$ $(0,01 \% \mathrm{v} / \mathrm{v})$, com aplicação até o ponto de escorrimento foliar. $\mathrm{O} \mathrm{GA}_{3}$ foi aplicado 14 dias antes da primeira colheita, enquanto AVG e 1-MCP foram aplicados sete dias antes da primeira colheita. A colheita foi realizada quando os frutos do tratamento controle apresentaram pelo menos $25 \%$ da superfície da epiderme com coloração vermelha.

Utilizou-se o delineamento blocos ao caso, com quatro repetições. Cada repetição foi constituída por 10 plantas (cada parcela com seis plantas úteis e duas de bordadura em cada extremidade da fileira). De cada parcela foram colhidos 25 frutos, os quais foram transportados ao laboratório e submetidos às análises físico-químicas. Foram realizadas as determinações de atributos de textura, acidez titulável (AT), sólidos solúveis (SS) e cor da epiderme.

Os atributos de textura foram analisados com um texturômetro eletrônico TAXT-plus ${ }^{\circledR}$ (Stable Micro Systems Ltd., Reino Unido), em termos de força necessária para o rompimento da epiderme e de força para a penetração na polpa e para a compressão do fruto inteiro. Para a quantificação da força necessária para o rompimento da epiderme e para a penetração na polpa, foi utilizada ponteira modelo PS2, com 2mm de diâmetro, a qual foi introduzida na polpa a uma profundidade de $5 \mathrm{~mm}$ com velocidades pré-teste, teste e pós-teste de 30,5 e $30 \mathrm{~mm} \mathrm{~s}^{-1}$, respectivamente. A resistência do fruto à compressão foi determinada usando-se uma plataforma plana, modelo P/75, com $75 \mathrm{~mm}$ de diâmetro, que exerceu uma força de compressão até uma deformação de $5 \mathrm{~mm}$ na superfície do fruto.

Os valores de AT foram obtidos por meio de uma amostra de $10 \mathrm{~mL}$ de suco dos frutos, previamente extraído de fatias transversais retiradas da região equatorial dos frutos e trituradas em uma centrífuga elétrica. Essa amostra foi diluída em $100 \mathrm{~mL}$ de água destilada e titulada com solução de $\mathrm{NaOH} 0,1 \mathrm{~N}$ até $\mathrm{pH}$ 8,1 , sendo os resultados expressos em meq $100 \mathrm{~mL}^{-1}$. Os teores de SS ( ${ }^{\circ}$ Brix) foram determinados por 
refratometria, utilizando-se o suco extraído conforme descrito para a AT, sendo realizada a correção do efeito da temperatura $\left(20^{\circ} \mathrm{C}\right)$. A cor da epiderme foi avaliada em termos de valores de ângulo 'hue' $\left(h^{\circ}\right)$ na região equatorial dos frutos, em dois lados opostos, com o auxílio de um colorímetro Minolta, modelo CR-400. O índice de cor vermelha foi determinada por meio de uma escala com índices de 1 a 4, com superfície do fruto pigmentada de vermelho equivalente a $0-25 \%$, 26-50\%, 51-75\% e 76-100\% para os índices 1, 2, 3 e 4, respectivamente.

Os dados foram submetidos à análise da variância (ANOVA), e as médias dos tratamentos foram comparadas pelo teste de Tukey a 5\% de probabilidade de erro, por meio do programa SAS.

\section{RESULTADOS E DISCUSSÃO}

Em todos os atributos de maturação avaliados, não foi observada a interação entre os fatores tratamentos pré-colheita com reguladores de crescimento e datas de colheita (Tabelas 1, 2 e 3).

Os atributos de resistência à penetração da polpa e à compressão do fruto apresentaram maiores valores nos frutos que receberam a aplicação précolheita dos reguladores, os quais não diferiram entre si, e a força para ruptura da epiderme foi mais elevada no tratamento com 1-MCP em relação ao tratamento controle (Tabelas 1 e 2). A resposta da textura dos frutos aos tratamentos com AVG e 1-MCP está diretamente relacionada aos seus efeitos sobre a redução na síntese e na ação de etileno, respectivamente. O etileno é necessário para a promoção na atividade de enzimas responsáveis pela redução da firmeza dos frutos (JOHNSTON et al., 2001; MAJUMDER \& MAZUMDAR, 2002). MAJUMDER \& MAZUMDAR
(2002) constataram que o aumento na atividade da enzima poligalacturonase foi altamente correlacionado à evolução de etileno. O mecanismo de ação do GA 3 sobre a manutenção da integridade da estrutura da parede celular e, consequentemente, da textura dos frutos parece estar relacionado ao seu efeito na redução da produção de etileno, reduzindo assim a atividade de enzimas hidrolíticas de parede celular (PECH et al., 1994; FERRI et al., 2002).

A AT não apresentou diferenças entre tratamentos (Tabela 2). Em maçãs 'Gala' e 'Fuji’ a aplicação pré-colheita de AVG também não influenciou a AT dos frutos (STEFFENS et al., 2006; STEFFENS \& BRACKMANN, 2006). Também não foi observado efeito significativo do tratamento com $\mathrm{GA}_{3}$ sobre a manutenção da AT em caqui ‘Fuyu’ (FERRI et al., 2004). Com relação ao 1-MCP, ARGENTA et al. (2003) observaram que a sua aplicação em pós-colheita reduziu a degradação dos ácidos em ameixas 'Laetitia’ durante o armazenamento. No entanto, essa divergência de resultados talvez esteja relacionada ao fato de que neste trabalho o 1-MCP foi aplicado em pré-colheita e os frutos foram avaliados no mesmo dia em que foram colhidos.

Os teores de SS foram mais elevados nos frutos do tratamento controle, o qual não diferiu do tratamento com AVG (Tabela 3). Possivelmente, os maiores valores de SS no tratamento controle estejam relacionados ao maior conteúdo de pectinas solúveis, uma vez que esses frutos apresentaram a menor firmeza da polpa. Relação inversa entre valores de firmeza de polpa e SS também foi observado em goiabas 'Pedro Sato’ armazenadas sob refrigeração (STEFFENS et al., 2008).

Os tratamentos com reguladores vegetais não afetaram o índice de cor (superfície da epiderme

Tabela 1 - Força para ruptura da epiderme e resistência à penetração da polpa de ameixas 'Laetitia’ em função da data de colheita e da aplicação pré-colheita de aminoetoxivinilglicina (AVG), ácido giberélico (GA $\mathrm{G}_{3}$ ) e 1-metilciclopropeno (1-MCP).

\begin{tabular}{|c|c|c|c|c|c|c|}
\hline \multirow{2}{*}{ Tratamentos pré-colheita } & \multicolumn{3}{|c|}{--------Força para ruptura da epiderme (N)-------- } & \multicolumn{3}{|c|}{--------Resistência à penetração da polpa (N)---- } \\
\hline & $1^{\text {a }}$ Colheita & $2^{\mathrm{a}}$ Colheita & Média & $1^{\text {a }}$ Colheita & $2^{\text {a }}$ Colheita & Média \\
\hline Controle & 11,1 & 10,5 & $10,8 b$ & 3,36 & 2,44 & $2,90 b$ \\
\hline AVG & 11,8 & 11,0 & $11,4 \mathrm{ab}$ & 3,72 & 2,64 & $3,18 a$ \\
\hline $\mathrm{GA}_{3}$ & 12,2 & 10,4 & 11,3ab & 3,89 & 2,63 & $3,26 a$ \\
\hline 1-MCP & 12,0 & 11,0 & $11,5 a$ & 3,59 & 2,86 & 3,23a \\
\hline Média & $11,9 \mathrm{~A}$ & $10,7 \mathrm{~B}$ & & $3,67 \mathrm{~A}$ & $2,63 \mathrm{~B}$ & \\
\hline CV (\%) & & 5,09 & & & 6,15 & \\
\hline
\end{tabular}

*Médias não seguidas pela mesma letra, maiúsculas na linha e minúsculas nas colunas, diferem pelo teste de Tukey a 5\% de probabilidade de erro.

Ciência Rural, v.39, n.5, ago, 2009. 
Tabela 2 - Resistência à compressão e acidez titulável (AT) de ameixas 'Laetitia’ em função da data de colheita e da aplicação pré-colheita de aminoetoxivinilglicina (AVG), ácido giberélico $\left(\mathrm{GA}_{3}\right)$ e 1-metilciclopropeno (1-MCP).

\begin{tabular}{|c|c|c|c|c|c|c|}
\hline \multirow{2}{*}{ Tratamentos pré-colheita } & \multicolumn{3}{|c|}{----------Resistência à compressão (N) ---------- } & \multicolumn{3}{|c|}{-----------AT (meq 100mL ${ }^{-1}$ ) ---------- } \\
\hline & $1^{\text {a }}$ Colheita & $2^{\underline{a}}$ Colheita & Média & $1^{\text {a }}$ Colheita & $2^{\mathrm{a}}$ Colheita & Média \\
\hline Controle & 113,5 & 77,6 & $95,5 b$ & 34,1 & 29,5 & $31,8 a$ \\
\hline AVG & 123,2 & 85,7 & $104,5 a$ & 35,2 & 24,7 & $29,9 a$ \\
\hline $\mathrm{GA}_{3}$ & 136,9 & 85,9 & $111,4 a$ & 32,9 & 23,7 & $28,3 a$ \\
\hline 1-MCP & 129,5 & 84,5 & $111,5 a$ & 33,0 & 22,4 & $27,7 \mathrm{a}$ \\
\hline Média & $127,4 \mathrm{~A}$ & $83,4 \mathrm{~B}$ & & $33,8 \mathrm{~A}$ & $25,3 \mathrm{~B}$ & \\
\hline CV (\%) & & 12,7 & & & 6,37 & \\
\hline
\end{tabular}

*Médias não seguidas pela mesma letra, maiúsculas na linha e minúsculas nas colunas, diferem pelo teste de Tukey a 5\% de probabilidade de erro.

com cor vermelha) (dados não apresentados), mas reduziram a intensidade de coloração vermelha (maiores valores de $h^{o}$ da epiderme) em relação ao tratamento controle (Tabela 3). Como a mudança na cor durante o amadurecimento de ameixas é um processo dependente de etileno (ARGENTA et al., 2003), isso explica a menor intensidade de coloração vermelha nos tratamentos com AVG e 1-MCP. Todavia, segundo LELIÉVRE et al. (1997), os processos envolvidos nas mudanças da cor podem ser dependentes ou independentes de etileno, de acordo com o tipo de pigmento envolvido e com a espécie de fruto. Dessa forma, o tratamento com GA também pode reduzir a intensidade de cor vermelha nos frutos devido ao seu efeito no retardo da maturação (FERRI et al., 2002 e 2004; AMARANTE et al., 2005)

Com o atraso na data de colheita, observouse que os frutos apresentaram uma evolução na cor da epiderme, tornando-se mais vermelhos. Além disso, foi observada uma diminuição nos valores de firmeza, AT e SS (Tabelas 1, 2 e 3), comportamento considerado normal durante o amadurecimento dos frutos (BOWEN \& WATKINS, 1997; WANG \& DILLEY, 2001; STEFFENS et al., 2006).

\section{CONCLUSÃO}

A aplicação pré-colheita de 1-MCP, AVG e $\mathrm{GA}_{3}$ retarda a maturação de ameixas 'Laetitia', pois mantém a textura e retarda a evolução da coloração vermelha da epiderme dos frutos.

\section{AGRADECIMENTOS}

Agradecemos à empresa Fruticultura Pilati pela parceria neste trabalho, que forneceu a área para realização deste experimento. Também ao Conselho Nacional de Desenvolvimento Científico e Tecnológico (CNPq) e a Universidade do Estado de Santa Catarina (UDESC) pela concessão da Bolsas de Iniciação Científica e de Produtividade em Pesquisa.

Tabela 3 - Sólidos solúveis (SS) e cor da epiderme (ângulo 'hue’; $h^{\circ}$ ) de ameixas 'Laetitia’ em função da data de colheita e da aplicação précolheita de aminoetoxivinilglicina (AVG), ácido giberélico $\left(\mathrm{GA}_{3}\right)$ e 1-metilciclopropeno (1-MCP).

\begin{tabular}{|c|c|c|c|c|c|c|}
\hline \multirow{2}{*}{ Tratamentos pré-colheita } & \multicolumn{3}{|c|}{-----------------SS ('Brix) ---------------- } & \multicolumn{3}{|c|}{ 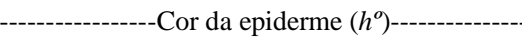 } \\
\hline & $1^{\text {a }}$ Colheita & $2^{\mathrm{a}}$ Colheita & Média & $1^{\mathrm{a}}$ Colheita & $2^{\text {a }}$ Colheita & Média \\
\hline Controle & 10,3 & 10,2 & $10,2 \mathrm{a}$ & 78,2 & 65,6 & $71,9 b$ \\
\hline AVG & 9,9 & 9,0 & $9,5 a b$ & 82,7 & 68,1 & $75,4 a$ \\
\hline $\mathrm{GA}_{3}$ & 9,6 & 7,7 & $8,6 b$ & 84,9 & 63,8 & $74,4 \mathrm{a}$ \\
\hline 1-MCP & 9,3 & 7,2 & $8,2 b$ & 87,6 & 71,5 & $79,6 a$ \\
\hline Média & $9,70 \mathrm{~A}$ & $8,62 \mathrm{~B}$ & & $83,9 \mathrm{~A}$ & $66,8 \mathrm{~B}$ & \\
\hline CV (\%) & & 8,70 & & & 14,1 & \\
\hline
\end{tabular}

*Médias não seguidas pela mesma letra, maiúsculas na linha e minúsculas nas colunas, diferem pelo teste de Tukey a 5\% de probabilidade de erro.

Ciência Rural, v.39, n.5, ago, 2009. 


\section{REFERÊNCIAS}

AMARANTE, C.V.T. do et al. Effect of aminoethoxyvinylglycine (AVG) on preharvest fruit drop and maturity of apples. Revista Brasileira de Fruticultura, Jaboticabal, v.24, n.3, p.661-664, 2002.

AMARANTE, C.V.T. do et al. A pulverização pré-colheita com ácido giberélico $\left(\mathrm{GA}_{3}\right)$ e aminoetoxivinilglicina (AVG) retarda a maturação e reduz as perdas de frutos na cultura do pessegueiro. Revista Brasileira de Fruticultura, Jaboticabal, v.27, n.1, p.1-5, 2005.

ARGENTA, L.C. et al. Ripening and quality of 'Laetitia' plums following harvest and cold storage as affected by inhibition of ethylene action. Pesquisa Agropecuária Brasileira, Brasilia, v.38, n.10, p.139-1148, 2003. Disponível em: <http://www.scielo.br/ s cie l o.ph p ? s c ri p t = s ci_art t ext \& pi d = S 0100 204X2003001000002\&lng=en\&nrm=iso\&tlng=en>. Doi: 10.1590/ S0100-204X2003001000002.

BOWEN, J.H.; WATKINS, C.B. Fruit maturity, carbohydrate and mineral content relationships with watercore in 'Fuji' apples. Postharvest Biology and Technology, Amsterdam, v.11, n.1, p.31-38, 1997. Disponível em: <http://www.sciencedirect.com/ science?_ob=ArticleURL\&_udi=B6TBJ-3RH6XC1$3 \&$ \&user $=687358 \&$ \&doc $=1 \&$ \& fmt $=\&$ \&_orig $=$ search \&_sort $=$ d \& vi e w $=$ c \&_a c c t $=$ C $000037899 \&$ \& vers i on $=$ $1 \&$ \& u r l V e r s i o n $=0 \&$ _ u s e r i d $=6873$ 58\&md5=e0400ccbb96feb6f905f27a9bfb486cd>. Doi: 10.1016/ S0925-5214(97)01409-9.

BRACKMANN, A. et al. Qualidade da maçã cv. 'Gala' tratada com 1-metilciclopropeno. Ciência Rural, Santa Maria, v.34, n.5, p.1415-1420, 2004. Disponível em: <http:// www.scielo.br/scielo.php?script=sci_arttext\&pid=S0103$84782004000500014 \& \operatorname{lng}=$ en $\& n r m=i s o \& t \operatorname{lng}=p t>$. Doi: $10.1590 / \mathrm{S} 0103-84782004000500014$

DAL CIN, V. et al. The ethylene biosynthetic and signal transduction pathways are differently affected by 1-MCP in apple and peach fruit. Postharvest Biology and Technology, Amsterdam, v.42, p.125-133, 2006. Disponível: <http:// w w w. s c i e n c e d i r e c t . c o m / science? ob=ArticleURL\&_udi=B6TBJ-4KYY3R6$2 \&$ _user $=687358 \&$ \& rdoc $=1 \&$ \& fmt $=\&$ \&_orig $=$ search $\&$ _ sort $=$ d \& vi e w = c \&_a c ct $=$ C $000037899 \&$ \& versio $\mathrm{n}=1 \&$ \& ur l Versi o $\mathrm{n}=0$ \&_u s e ri d = 687358 \& md5=ae11bb321c332ba90e63658889e0ef2d $>$. Doi: 10.1016/ j.postharvbio.2006.06.008.

FERRI, V.C. et al. Controle da maturação de caquis 'Fuyu', com o uso de aminoetoxivinilglicina e ácido giberélico. Revista Brasileira de Fruticultura, Jaboticabal, v.24, n.2, p.344-347, 2002. Disponível em: <http://www.scielo.br/ s cielo.php? script = sci__arttext \& pid = S 0100 $29452002000200014 \& \operatorname{lng}=$ en $\& n r m=$ iso $\& \operatorname{lng}=p t>$. Doi 10.1590/S0100-29452002000200014.

FERRI, V.C. et al. Ácido giberélico no retardamento da maturação de caquis (Diospyrus kaki, L.) cultivar 'Fuyu'. Ciência e Tecnologia dos Alimentos, Campinas, v.24, n.1, p.1-5, 2004.

JOHNSTON, J.W. et al. Temperature induces differential softening responses in apple cultivars. Postharves Biology and Technology, Amesterdam, v.23, n.3, p.185196, 2001. Disponível em: <http://www.sciencedirect.com/
science?_ob=ArticleURL\&_udi=B6TBJ-44BM6WY$2 \&$ \&user $=687358 \&$ \&doc $=1 \&$ _fmt $=$ \&_orig $=$ search\&_sort $=$ d\&view $=$ c \&_a c ct $=$ C $000037899 \&$ \& version $=1 \&$ \&_url Ve

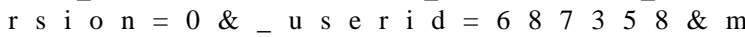
d5=3cc3b5954f4936494acc83febbbe4946>. Doi: 10.1016 S0925-5214(01)00127-2

LELIÈVRE, J. M. et al. Ethylene and fruit ripening. Physiologia Plantarum, Copenhagen, v.101, p.727-739, 1997.

MAJUMDER, K.; MAZUMDAR, B.C. Changes of pectic substances in developing fruits of cape-gooseberry (Physalis peruviana L.) in relation to the enzyme activity and evolution of ethylene. Scientia Horticulturae, Alexandria, v.96, n.1-4, p.91-101, 2002. Disponível em: <http://www.sciencedirect.com/ science?_ob=ArticleURL\&_udi=B6TC3-45 Y6H6T$2 \&$ user $=687358 \&$ rdoc $=1 \&$ fmt $=\&$ orig $=$ search \& sort $=$ d \& vi e w $=$ c \&_a c ct $=$ C $000037899 \&$ _version $=1$ \&_u r l V e r si o n $=0$ \&_u se ri d =6 67358 \& md5=1c21cf71e7267429d8f86239c2bc2fe9>. Doi: 10.1016/ S0304-4238(02)00079-1.

PECH, J.C. et al. Postharvest physiology of climacteric fruits: recent development in the biosynthesis and action of ethylene. Sciencia Alimentaria, Toulouse, v. 14, n.1, p. 3-14, 1994.

PETRI, J.L. et al. Efeito de aminoetoxivinilglicine (AVG) na maturação de frutos de ameixeira. In: ENCONTRO NACIONAL DE FRUTICULTURA DE CLIMA TEMPERADO - ENFRUTE, 8., 2005, Fraiburgo. Anais... Caçador: EPAGRI, 2005. p.313-314

POZO, L. et al. Differential effects of 1-methylcyclopropene on citrus leaf and mature fruit abscision. Journal of American Society for Horticultural Science, Alexandria, v.129, p.473478, 2004.

STEFFENS, C.A. et al. Maçã 'Gala' armazenada em atmosfera controlada e tratada com aminoetovinilglicina e ethephon. Pesquisa Agropecuária Brasileira, v.40, n.9, p.837-843, 2005b. Disponível em: <http://www.scielo.br/ scielo.ph p ? s cript = sci_art text \& pid = S $0100-$ 204X2005000900001\&lng $=$ en \&nrm $=$ iso\&tlng $=p t>$. Doi: 10.1590/S0100-204X2005000900001.

STEFFENS, C.A. et al. Queda pré-colheita de maçãs 'Gala' e 'Fuji'com aminoetoxivinilglicina e ethephon. Revista Brasileira de Agrociência, v.11, n.3, p.329-332, 2005a.

STEFFENS, C. A.; BRACKMANN, A. Maturação da maçã 'Fuji' com aplicação pré-colheita de aminoetoxivinilglicina e ethephon. Revista da Faculdade de Zootecnia, Veterinária e Agronomia, Uruguaiana, v.13, n.2, p. 176-184, 2006.

STEFFENS, C.A. et al. Maturação da maçã 'Gala’ com a aplicação pré-colheita de aminoetoxivinilglicina e ethephon. Ciência Rural, v.36, n.2, p. 434-440, 2006. Disponível em: <http:// www.scielo.br/scielo.php?script $=$ sci_arttext $\&$ pid $=$ S010384782006000200012 \&lng $=$ en $\& n r m=$ iso \& $\operatorname{lng}=p t>$. Doi $10.1590 / \mathrm{S} 0103-84782006000200012$.

STEFFENS, C.A. et al. Tolerância ao dano pelo frio em goiabas 'Pedro Sato' submetidas ao condicionamento térmico. Biotemas, Florianópolis, v.21, n.3, p.75-80, 2008.

WANG, Z.; DILLEY, D.R. Aminoethoxyvinylglycine, combined with ethephon, can enhance red color development without over-ripening apples. HortScience, Alexandria, v.36, n.2, p.328-331, 2001. 